\title{
Periodic acid-Schiff staining method for function detection of liver cells is affected by $2 \%$ horse serum in induction medium
}

\author{
HUI HUI ${ }^{1-4 *}$, WENJUN MA $^{1-3^{*}}$, JIEJIE CUI $^{2,3}$, MENGJIA GONG ${ }^{2,3}$, YI WANG $^{1}$, \\ YUANYUAN ZHANG ${ }^{2,3}$, TONGCHUAN HE ${ }^{2,3}$, YANG BI ${ }^{1-3}$ and YUN HE ${ }^{1-3}$ \\ ${ }^{1}$ Department of Pediatric Surgery; ${ }^{2}$ Stem Cell Biology and Therapy Laboratory; ${ }^{3}$ Ministry of Education Key Laboratory \\ of Child Development and Disorders, The Children's Hospital of Chongqing Medical University, Chongqing 400014; \\ ${ }^{4}$ Department of Pediatric Surgery, Wuxi Children's Hospital Affiliated to Nanjing Medical University, \\ Wuxi, Jiangsu 214023, P.R. China
}

Received March 22, 2016; Accepted March 8, 2017

DOI: $10.3892 / \mathrm{mmr} .2017 .7587$

\begin{abstract}
Developing a thorough understanding of experimental methods of hepatic differentiation in hepatic progenitor cells (HPCs) should expand the knowledge of hepatocyte induction in vitro and may help to develop cell transplantation therapies for the clinical usage of HPCs in liver diseases. A previous induction method effectively induced differentiation and metabolic abilities in HPCs. Periodic acid-Schiff (PAS) staining is used to identify glycogen synthesis and hepatocyte function; however, this method failed to detect induced hepatocytes. The present study aimed to investigate the possible factors affecting the previous confusing results of PAS staining. Removal of single induction factors, including dexamethasone, hepatic growth factor and fibroblast growth factor 4 from the induction media did not restore PAS staining, whereas replacement of $2 \%$ horse serum (HS) with $10 \%$ fetal bovine serum (FBS) significantly increased the number of PAS positive cells. Following 12 days of basal induction, replacing the induction medium with media containing $10 \%$ FBS for 12-72 h significantly improved PAS staining, but did not influence indocyanine green uptake. Furthermore, incubation in induction medium with $10 \%$ FBS following 12 days of normal induction did not affect the expression of hepatic markers and mature function of HPCs. Therefore, the present study suggested that $2 \%$ HS in the induction medium did not affect the hepatic function of induced cells, but did affect glycogen storage, whereas replacement of medium with $10 \%$ FBS
\end{abstract}

Correspondence to: Dr Yun He, Department of Pediatric Surgery, The Children's Hospital of Chongqing Medical University, 136 Zhongshan Er Road, Chongqing 400014, P.R. China

E-mail: dr_yunhe@hospital.cqmu.edu.cn

*Contributed equally

Key words: periodic acid-Schiff staining, hepatic progenitor cells, induction, horse serum in advance of PAS staining may restore the failure of PAS staining in low serum concentrations of induced hepatocytes.

\section{Introduction}

Cell-based therapies are a promising alternative strategy to liver organ transplantation for the treatment of liver disease $(1,2)$. Stem or progenitor cells have been considered as potential sources of cells for hepatocyte replacement and functional recovery due to their characteristics of self-renewal, generation of progeny and multiple-differentiation $(3,4)$. However, recent studies have reported that stem cell-derived mature liver cells may be a better option than stem cells for liver cell transplantation therapy $(5,6)$. Furthermore, the efficiency of hepatic differentiation of stem cells is low, and although the induced cells express liver-specific markers, they fail to exhibit adequate hepatocyte functionality (7-9). Thus, an effective and reliable method to induce hepatic differentiation of stem cells is increasingly important and needs to be investigated.

In preliminary work, a relatively valid method to induce hepatic differentiation and maturation of hepatic progenitor cells (HPCs) was reported. The combination of $2 \%$ horse serum (HS), $0.1 \mu \mathrm{mol} / 1$ dexamethasone (Dex), $10 \mathrm{ng} / \mathrm{ml}$ hepatic growth factor (HGF) and $20 \mathrm{ng} / \mathrm{ml}$ fibroblast growth factor 4 (FGF4) effectively induced the maturation and function of HPCs, but resulted in fewer periodic acid-Schiff (PAS) stain positive cells compared with the untreated group $(10,11)$. Therefore, PAS staining may not be a suitable method for testing the hepatocyte function of induced stem cells. PAS staining is an important method to mark carbohydrates, and is commonly used to evaluate glycogen storage and function of mature hepatocytes $(12,13)$. To allow the use of this important experimental approach in the detection of functional hepatocytes following the induction of differentiation, the possible reasons need to be elucidated.

In the present study, $2 \%$ HS was demonstrated to be an important factor affecting PAS staining results, but did not affect the differentiation, maturation and function of induced HPCs. By replacing the induction medium with media containing $10 \%$ fetal bovine serum (FBS) following induction, glycogen synthesis and accumulation of HPCs may be 
recovered, which may restore the ability to perform PAS staining. The present study may, therefore, aid in the application of the PAS staining method during detection of induced hepatocytes cultured in $2 \% \mathrm{HS}$.

\section{Materials and methods}

Cell culture and chemicals. Hepatic progenitor cells were obtained from the livers of mouse embryos at 14.5 days post coitus and named as hepatic progenitor 14.5d (HP14.5d) cells, as described by Bi et al (14). Cells were maintained in complete Dulbecco's modified Eagle's medium (DMEM; Gibco; Thermo Fisher Scientific, Inc., Waltham, MA, USA) supplemented with $10 \%$ FBS (Gibco; Thermo Fisher Scientific, Inc.), 100 units $/ \mathrm{ml}$ penicillin and $100 \mu \mathrm{g} / \mathrm{ml}$ streptomycin at $37^{\circ} \mathrm{C}$ in $5 \% \mathrm{CO}_{2}$. HP14.5d cells were cultured with $0.1 \mu \mathrm{mol} / 1 \mathrm{Dex}$, $10 \mathrm{ng} / \mathrm{ml} \mathrm{HGF}$ and $20 \mathrm{ng} / \mathrm{ml} \mathrm{FGF4} \mathrm{in} \mathrm{DMEM} \mathrm{containing} \mathrm{2 \%}$ $\mathrm{HS}$ (Gibco; Thermo Fisher Scientific, Inc.) at $37^{\circ} \mathrm{C}$ in a $5 \% \mathrm{CO}_{2}$ atmosphere for 12 days to induce differentiation, as previously described (11). To detect the effect of serum change on the function and PAS staining result of induced cells, the induction medium was replaced with DMEM supplemented with $10 \% \mathrm{FBS}, 0.1 \mu \mathrm{mol} / 1$ Dex, $10 \mathrm{ng} / \mathrm{ml} \mathrm{HGF}$ and $20 \mathrm{ng} / \mathrm{ml} \mathrm{FGF} 4$. Unless otherwise indicated, all chemicals were purchased from Sigma-Aldrich; Merck KGaA (Darmstadt, Germany).

Gaussia luciferase reporter assay (Gluc assay). Prior to induction, HP14.5d cells $\left(8 \times 10^{4}\right)$ were seeded in 24 -well culture plates at an initial confluence of $30 \%$ and transfected with a homemade plasmid containing an albumin (ALB) promoter-driven luciferase reporter gene (pSEB-ALB-Gluc), using Lipofectamine ${ }^{\circledR} 2000$ (Invitrogen; Thermo Fisher Scientific, Inc.) as the transfection reagent (15). Briefly, the ALB promoter was amplified by polymerase chain reaction and inserted into the multi-cloning site of a pBGLuc vector, as previously described $(14,15)$. The sequence of the pBGLuc plasmid sequence can be accessed at: http://www. boneandcancer.org/MOLab\%20Vectors\%20after\%20Nov\%20 $1 \% 202005 /$ pBGLuc.pdf. At the indicated time points, culture medium was collected and GLuc activity was assayed using the Gaussia Luciferase Assay kit (New England Biolabs, Inc., Ipswich, MA, USA). All measurements were performed in triplicate.

Reverse transcription-quantitative PCR (RT-qPCR). Total RNA was extracted using TRIzol ${ }^{\circledR}$ reagent (Thermo Fisher Scientific, Inc.), according to the manufacturer's protocol. Total RNA (10 mg) was reverse transcribed into cDNA with hexamer primers using Superscript II reverse transcriptase (Invitrogen; Thermo Fisher Scientific, Inc.). Primers specific for the genes of interest were designed using Primer3 software version 2.3 .7 (source code available at: http://sourceforge. net/projects/primer3/) $(16,17)$ and are presented in Table I. SYBR-Green-based quantitative real-time PCR analysis (Bioteke Corporation, Beijing, China) was carried out under the following conditions: with 40 cycles of denaturation at $94^{\circ} \mathrm{C}$ for $20 \mathrm{sec}$, annealing at $55^{\circ} \mathrm{C}$ for $20 \mathrm{sec}$ and extension at $70^{\circ} \mathrm{C}$ for $20 \mathrm{sec}$. Gene expression was quantified using the $2^{-\Delta \Delta C q}$ method (18). Data are reported as the fold change of control, following normalization against GAPDH expression.
Table I. Reverse transcription-quantitative polymerase chain reaction primers.

\begin{tabular}{lc}
\hline Gene target & \multicolumn{1}{c}{ Primer sequence $\left(5^{\prime}\right.$-3') } \\
\hline GAPDH & F-GGCTGCCCAGAACATCAT \\
& R-CGGACACATTGGGGGTAG \\
AFP & F-ACGAGGAAAGCCCCTCAG \\
& R-GCCATTCCCTCACCACAG \\
ALB & F-CCAGACATTCCCCAATGC \\
& R-CAAGTTCCGCCCTGTCAT \\
CK18 & F-CTGGGCTCTGTGCGAACT \\
& R-ACAGAGCCACCCCAGACA \\
TAT & F-ACCTTCAATCCCATCCGA \\
& R-TCCCGACTGGATAGGTAG
\end{tabular}

GAPDH, glyceraldehyde-3-phosphate dehydrogenase; F, forward; R, reverse; AFP, $\alpha$ fetoprotein; ALB, albumin; CK18, keratin 18; TAT, tyrosine aminotransferase.

Periodic acid-Schiff (PAS) staining. Cells were seeded in 24-well plates and induced for 12 days, then fixed with $4 \%$ paraformaldehyde for $10 \mathrm{~min}$. Following washing with PBS, cells were incubated with $0.5 \%$ periodic acid solution for $5 \mathrm{~min}$, then stained with Schiff's reagent for $15 \mathrm{~min}$, followed by counterstaining with hematoxylin solution for $2 \mathrm{~min}$. All steps were performed at room temperature, and cells were rinsed with tap water after each step. At least 10 non-overlapping fields of view in each group were recorded under a microscope and cells with cytoplasm stained purple-red were counted as positive.

Indocyanine green (ICG) uptake. Induced cells were washed with PBS and incubated in complete DMEM medium containing $1 \mathrm{mg} / \mathrm{ml}$ freshly prepared ICG reagent at $37^{\circ} \mathrm{C}$ for $1 \mathrm{~h}$. At least 10 non-overlapping fields of view were recorded under the microscope and cells with green nuclear staining were counted as positive. Cells were then incubated with ICG-free complete medium at $37^{\circ} \mathrm{C}$ for $6 \mathrm{~h}$ to detect the function of ICG release.

Statistical analysis. Data are presented as the mean \pm standard deviation and were analyzed using SPSS software version 19.0 (IBM SPSS, Armonk, NY, USA). The statistical significance of the differences between groups was assessed using a two-tailed Student's t-test for pair-wise comparisons, or a one-way analysis of variance followed by a post hoc Student-Newman-Keuls test for multiple comparisons. $\mathrm{P}<0.05$ was considered to indicate a statistically significant difference.

\section{Results}

Successful induction of HPCs maturation and differentiation in vitro. The differentiation of HP14.5d cells was evaluated by exploring morphological and hepatic related markers. Uninduced HP14.5d cells exhibited large, elongated and irregular polygonal morphologies with one or two nuclei (Fig. 1A, top panel). Following 3 days of induction, $80 \%$ of treated cells 


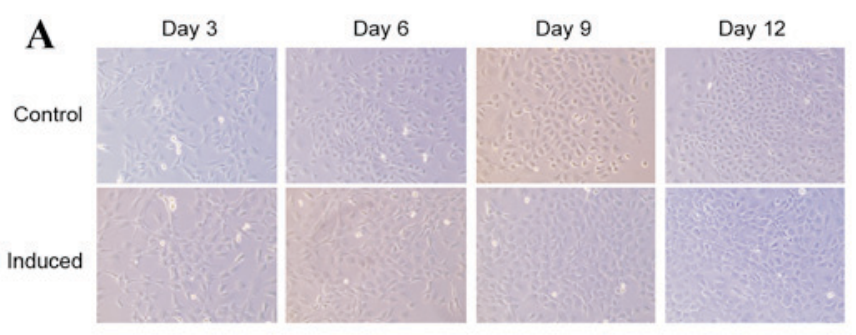

B

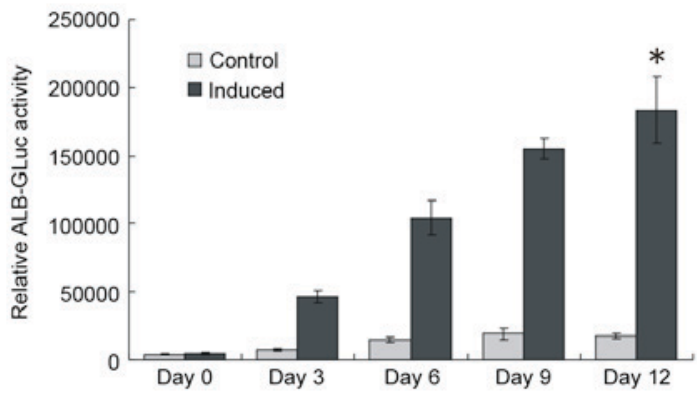

C

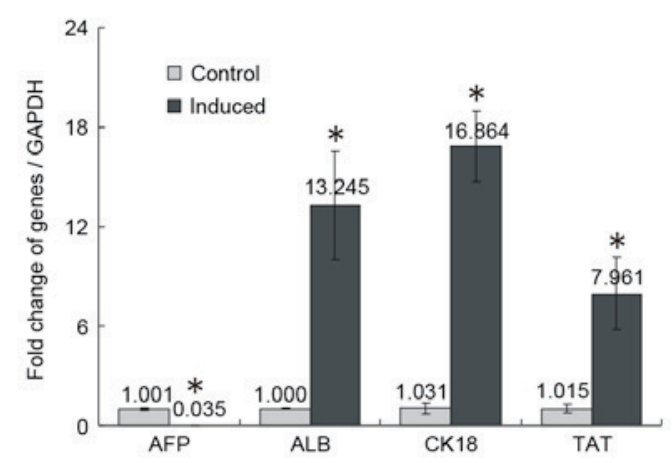

Figure 1. Induced differentiation of HP14.5d cells in vitro. (A) Cell morphology of uninduced control and induced HP14.5d cells following 3,6,9 and 12 days of induction (original magnification, x200). (B) ALB-GLuc activity in HP14.5d cells following 3, 6, 9 and 12 days of induction. ${ }^{*} \mathrm{P}<0.05$ vs. control $(n=3)$. (C) Semi-quantitative RT-PCR analysis of mRNA expression levels of hepatic related genes AFP, ALB, CK18 and TAT. RT-PCR was performed following 12 days of induction. ${ }^{*} \mathrm{P}<0.05$ vs. control $(\mathrm{n} \geq 3)$. ALB, albumin; GLuc, Gaussia luciferase; RT-PCR, reverse transcription-polymerase chain reaction; AFP, $\alpha$ fetoprotein; CK18, keratin 18; TAT, tyrosine aminotransferase.

fused; all cells were fused on day 6 . On induction day 12 , the induced cells were arranged closely like paving stones and the nucleus/cytoplasm (N/C) ratio was decreased (Fig. 1A, bottom panel). However, the increase in cell density in the induced group was smaller compared with the control group (Fig. 1A), potentially due to the low serum concentration in the induction medium.

To detect relative ALB expression levels, the pSEBALB-GLuc reporter plasmid was transfected into the HP14.5d cells prior to induction. Relative ALB-GLuc activity was assessed on days $0,3,6,9$ and 12 of induction with the $2 \% \mathrm{HS} / \mathrm{Dex} / \mathrm{HGF} / \mathrm{FGF} 4$ induction medium. The GLuc assay evaluates the activity of the ALB promoter, which indirectly indicates ALB expression levels in cells $(14,15,19)$. Compared with the control group, the relative ALB-GLuc activity began to increase on day 3 of treatment, and continued to grow until day 12 ( $\mathrm{P}<0.05$; Fig. 1B). RT-qPCR demonstrated that AFP expression decreased significantly following 12 days of induction compared with the control group $(\mathrm{P}<0.05$; Fig. $1 \mathrm{C})$, whereas the expression of the liver-specific markers ALB,
CK-18 and TAT was significantly upregulated compared with the control group $(\mathrm{P}<0.05$; Fig. $1 \mathrm{C})$.

Induction in medium with $2 \%$ HS promotes ICG uptake, but does not increase the number of positive PAS stained cells. ICG uptake and PAS staining are methods commonly used to detect the metabolism and synthesis function of liver cells $(14,20,21)$. ICG uptake and PAS staining of HP14.5d cells were examined following 12 days of induction (Fig. 2A). Uninduced control HP14.5d cells exhibited low levels of ICG uptake and glycogen storage (Fig. 2A, left panel). In the induced group, the number of ICG-positive stained cells was markedly increased compared with the control group, as expected (Fig. 2A). Therefore, as indicated by the cellular morphology (Fig. 1A), the expression of hepatic stem cell markers (Fig. 1B and C) and ICG uptake (Fig. 2A, bottom panel), the induction of HP14.5d cells led to hepatic differentiation. However, fewer PAS-positive cells were identified in the induced HP14.5d cells compared with in the uninduced control group (Fig. 2A, top panel).

In order to establish which component of the induction medium may impact the PAS staining result, the medium was altered by omission of each component individually (Fig. 2B). Similarly, fewer PAS-positive cells were identified among induced HP14.5d cells compared with in the uninduced control group (Fig. 2B-a and b). Omission of Dex (Fig. 2B-c), HGF (Fig. 2B-d), and FGF4 (Fig. 2B-e) from the induction medium did not alter PAS staining compared with the normal induction medium (Fig. 2B-b). However, replacement of $2 \%$ HS with $10 \%$ FBS (Fig. 2B-f), resulted in a visible increase in the number of PAS-positive cells compared with cells in the complete induction medium (Fig. 2B-f). Therefore, these results suggested that the $2 \% \mathrm{HS}$ in the induction medium is the factor affecting the results of PAS staining.

Replacing the induction medium with media containing $10 \%$ FBS affects the results of PAS staining. Investigations were then performed to evaluate whether $2 \% \mathrm{HS}$ affected glycogen storage in induced liver cells or just affected the results of the PAS staining method. On induction day 12, the induction medium was replaced with medium containing $10 \% \mathrm{FBS}+0.1 \mu \mathrm{mol} / 1 \mathrm{Dex}+10 \mathrm{ng} / \mathrm{ml} \mathrm{HGF}+20 \mathrm{ng} / \mathrm{ml} \mathrm{FGF} 4$. PAS staining was then performed 12, 24, 48 and $72 \mathrm{~h}$ following incubation (Fig. 3A).

While limited purple staining was observed in the uninduced control in medium contaning 10\% FBS (Fig.3A-a), the number of purple stained cells in the induced group in $2 \%$ HS-containing medium without a shift to $10 \%$ FBS-containing induction medium (Fig. 3A-b, induced-0 h group) was significantly smaller compared with in the uninduced control group. Increasing numbers of PAS-positive cells were observed in the induced groups in which the medium was shifted to medium containing $10 \%$ FBS instead of $2 \%$ HS at different time points prior to PAS staining $(\mathrm{P}<0.05$; Fig. $3 \mathrm{~A})$. Compared with cells that were not shifted to media with $10 \%$ FBS (Fig. 3A-b), the number of PAS-positive cells increased slightly upon media shift and incubation for $12 \mathrm{~h}$ (Fig. 3A-c). The number of purple stained cells increased further following 24 (Fig. 3A-d) and $48 \mathrm{~h}$ (Fig. 3A-e) of incubation with 10\% FBS induction medium, but no further increase was observed following $72 \mathrm{~h}$ of incubation with $10 \%$ FBS induction medium compared 
A

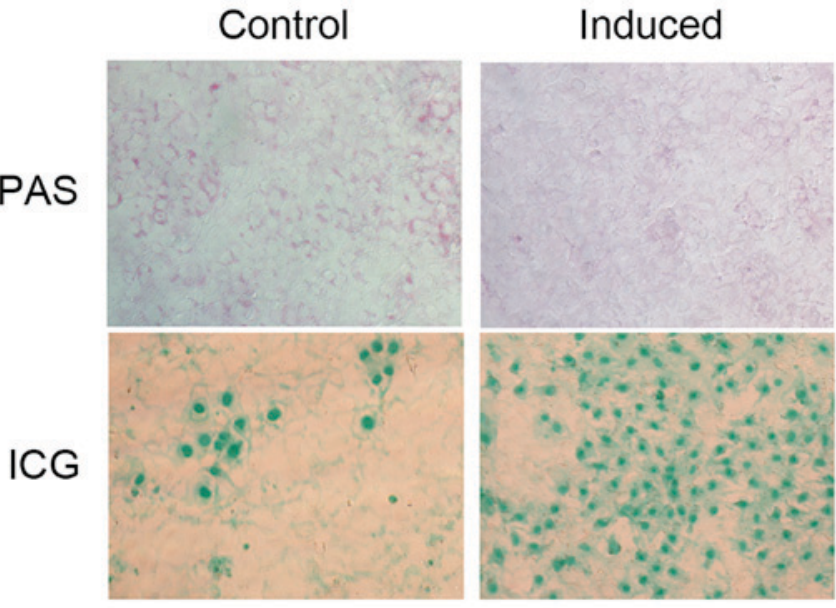

B
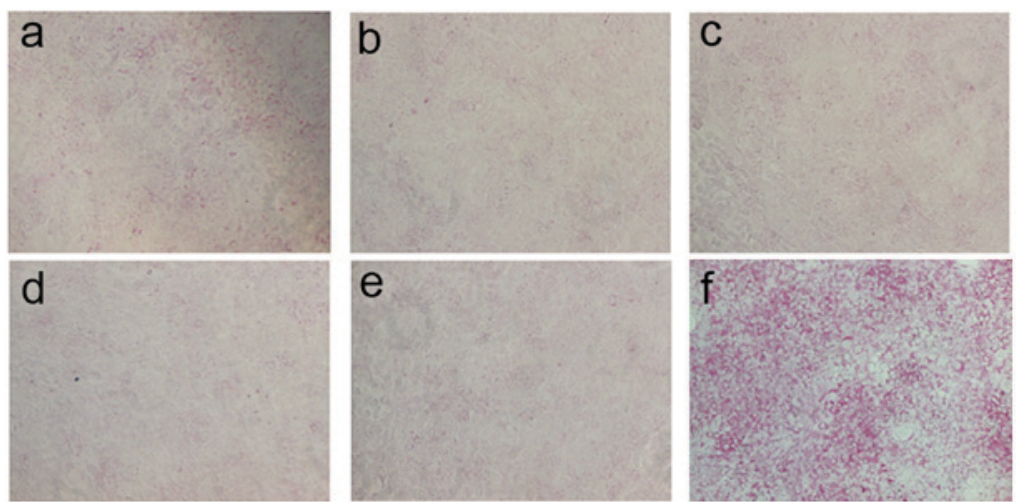

Figure 2. HS influences PAS staining in induced HP14.5d cells. (A) PAS staining and ICG uptake demonstrated the glycogen storage and transport-metabolism function, respectively, of HP14.5d cells induced for 12 days. Uninduced HP14.5d cells were set up as a control. Photomicrographs were captured under x200 magnification. (B) PAS staining of HP14.5d cells following induction for 12 days in: (a) complete DMEM containing 10\% FBS (uninduced); (b) induction medium (DMEM containing $0.1 \mu \mathrm{mol} / 1$ Dex, $10 \mathrm{ng} / \mathrm{ml} \mathrm{HGF,} 20 \mathrm{ng} / \mathrm{ml} \mathrm{FGF4}$ and 2\% HS); (c) induction medium without Dex; (d) induction medium without HGF; (e) induction medium without FGF4; (f) induction medium with $2 \%$ HS replaced with $10 \%$ FBS. Photomicrographs were captured under x100 magnification. Representative images of $\geq 3$ independent experiments are presented. HS, horse serum; PAS, periodic acid-Schiff; ICG, indocyanine green; DMEM, Dulbecco's modified Eagle's medium; FBS, fetal bovine serum; Dex, dexamethasone; HGF, hepatic growth factor; FGF4, fibroblast growth factor 4.

with $48 \mathrm{~h}$ of incubation (Fig. 3A-f). A highly significant difference was detected in PAS-positive cell numbers between the induced- $0 \mathrm{~h}$ and induced- $48 \mathrm{~h}$ groups. At the same time points following induction and media shift, ICG uptake was demonstrated not to be influenced by the shift to incubation in 10\% FBS medium (Fig. 3B). These results indicated that the serum condition did not affect the hepatic function of induced cells, but PAS staining method.

Replacing cell induction medium with media containing 10\% FBS following 12 days of induction does not affect the differentiation of HP14.5d cells. Investigations into whether changing the induction medium affects the differentiation of induced HP14.5d cells were then performed. As demonstrated in Fig. 4A, the cell morphology of induced HP14.5d cells was not changed by shifting into media containing $10 \%$ FBS. However, the cell numbers in the group incubated for $72 \mathrm{~h}$ in the replacement media were higher than in the unshifted group (Fig. 4A), which may be due to better nutrition and increased cell proliferation in the condition with $10 \%$ FBS. Replacing the induction media with media containing $10 \%$ FBS had no significant effect on the relative ALB-GLuc activity of induced HP14.5d cells, regardless of time of incubation, compared with the unshifted cells (Fig. 4B). In addition, the medium change had no effect on expression of hepatic specific markers of induced HP14.5d cells, compared with the unshifted cells (Fig. 4C). These results, therefore, demonstrated that shifting cells into media with $10 \%$ FBS following normal induction for 12 days did not affect the differentiation of HPCs.

\section{Discussion}

Liver stem cell transplantation technology is based on the differentiation potential and proliferation ability of liver stem cells $(22,23)$. Compared with undifferentiated stem cells, induced cells that undergo maturation and differentiation in vitro prior to transplantation exhibit greater abilities to compensate or rebuild liver function (24-26). In order to make the liver stem cells more efficiently differentiate into mature and functional liver cells, recent studies have attempted to induce liver stem cells by providing a series of stimulation factors $(27,28)$. As a prospective seed cells for transplantation, HPCs derived from liver tissues at an early stage of embryonic development can be stably expanded in vitro and possess the potential of bidirectional differentiation into both hepatocytic 
A

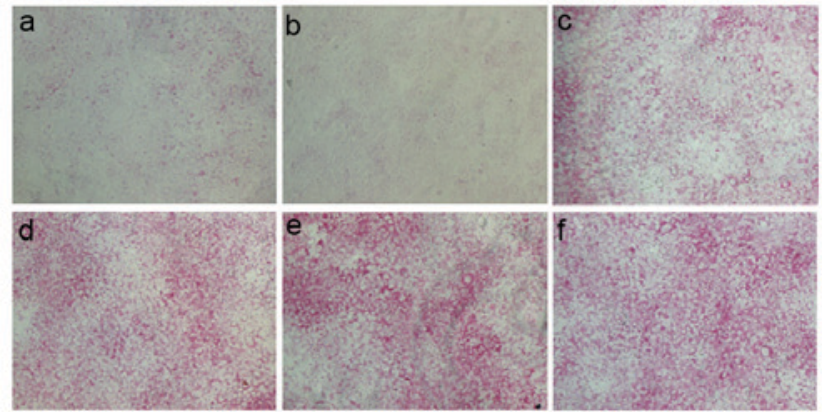

B

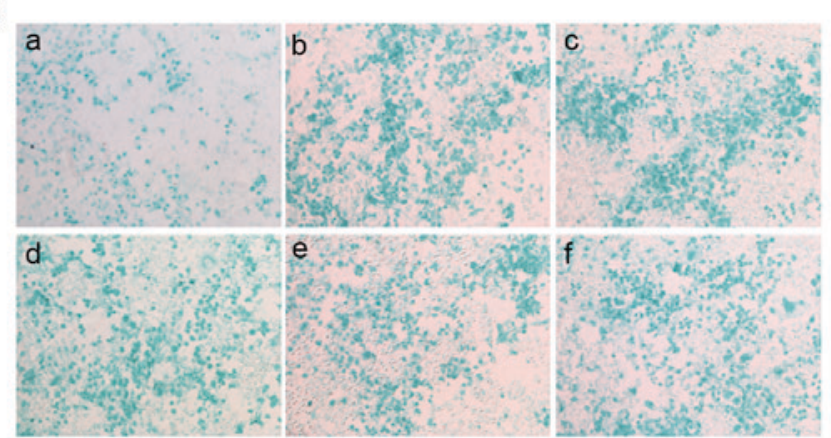

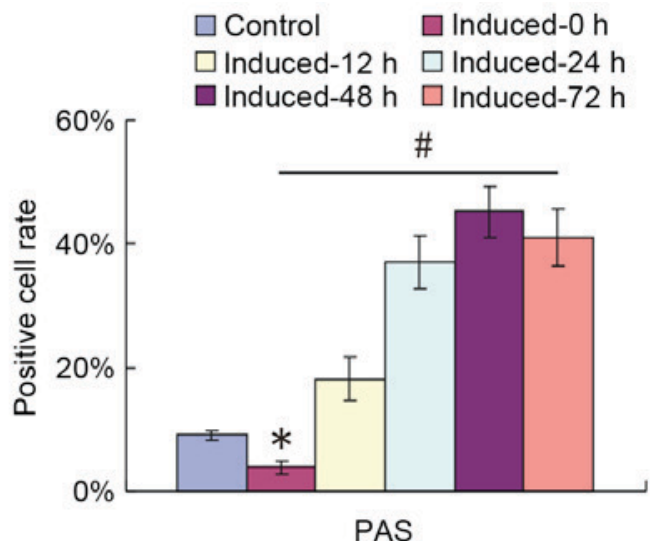

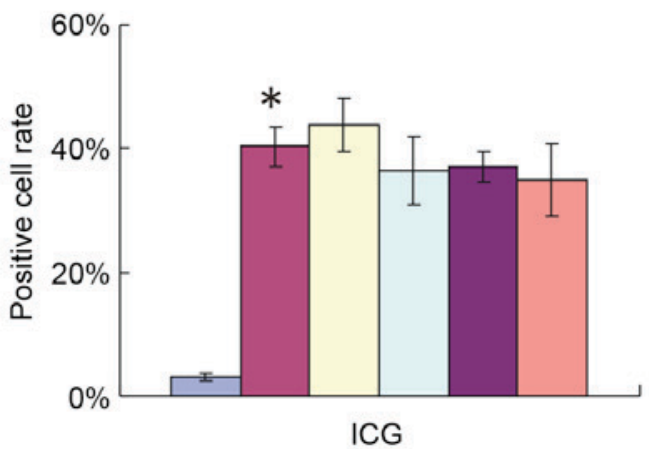

Figure 3. Replacement of 2\% HS with 10\% FBS ahead of PAS staining detection reflects the glycogen storage and accumulation function of induced HP14.5d cells. HP14.5d cells were treated with DMEM containing $2 \% \mathrm{HS}+0.1 \mu \mathrm{mol} / 1 \mathrm{Dex}+10 \mathrm{ng} / \mathrm{ml} \mathrm{HGF}+20 \mathrm{ng} / \mathrm{ml}$ FGF4 for $12 \mathrm{days}$, then the induction medium was replaced with complete DMEM with $10 \% \mathrm{FBS}+0.1 \mu \mathrm{mol} / 1 \mathrm{Dex}+10 \mathrm{ng} / \mathrm{ml} \mathrm{HGF}+20 \mathrm{ng} / \mathrm{ml}$ FGF4 for different time periods. (A) PAS staining and (B) ICG uptake were assessed at 12, 24, 48 and $72 \mathrm{~h}$ after the induction medium was changed. (a) Uninduced HP14.5d cells as control; (b) HP14.5d cells induced for 12 days with no media shift; (c) HP14.5d cells induced for 12 days and induction medium changed for 12 h; (d) HP14.5d cells induced for 12 days and induction medium changed for $24 \mathrm{~h}$; (e) HP14.5d cells induced for 12 days and induction medium changed for 48 h; (f) HP14.5d cells induced for 12 days and induction medium changed for $72 \mathrm{~h}$. Photomicrographs were captured under x100 magnification. Representative images and data from $\geq 3$ independent experiments are presented. ${ }^{\mathrm{P}}<0.05$ vs. control; ${ }^{\text {P }}<0.05$ among different induced groups. HS, horse serum; FBS, fetal bovine serum; PAS, periodic acid-Schiff; DMEM, Dulbecco's modified Eagle's medium; Dex, dexamethasone; HGF, hepatic growth factor; FGF4, fibroblast growth factor 4; ICG, indocyanine green.

and cholangiocytic lineages $(29,30)$. In previous studies, this laboratory reported a relatively effective method to induce hepatic differentiation and maturation of HPCs $(10,11)$; however, the results of PAS staining, a method typically used to evaluate the glycogen storage function of mature liver cells, was inconsistent with the expression of hepatic marker genes and metabolic detoxification of ICG uptake. In the present study, factors that may affect the outcome of PAS staining in measurements of liver function were investigated.

As previously, this study demonstrated that this induction method effectively increased the ALB-Gluc activity, hepatic marker expression and ICG uptake of HPCs, indicating their maturation and differentiation. However, PAS staining in induced cells was less than in the uninduced control. The induction medium was primarily composed of four added factors: $2 \% \mathrm{HS}, 0.1 \mu \mathrm{mol} / \mathrm{l}$ Dex, $10 \mathrm{ng} / \mathrm{ml} \mathrm{HGF}$ and $20 \mathrm{ng} / \mathrm{ml} \mathrm{FGF4.}$ Therefore, removal of single inducing factors one by one was necessary. In previous studies, Dex, HGF and/or FGF4 have been reportedly used to induce bone marrow mesenchymal stem cells, hematopoietic cells, or mouse embryonic stem cells differentiation to hepatic cell lines, and PAS staining was available (31-33). In the present study, removal of Dex, HGF or FGF4 did not change the number of positive PAS stained cells. However, when $2 \%$ HS was replaced with $10 \% \mathrm{FBS}$, the number of purple stained cells significantly increased.
Therefore, it was proposed that the low concentration of horse serum in the induction media was an important factor affecting the PAS staining results.

Investigations were then performed into whether induction in $2 \%$ HS serum affected the glycogen storage function of induced liver cells or just affected the PAS staining. Two possible causes of negative PAS staining were considered: i) Induced HP14.5d cells lost the function of glycogen synthesis or ii) cells were functional but no glycogen was present in the cells because of the $2 \%$ HS in the culture medium. To examine the possible causes, following treatment of HP14.5d cells with induction medium for 12 days, the $2 \%$ HS was removed and replaced with $10 \%$ FBS for different time periods prior to PAS staining assay. When induced HP14.5d cells were cultured in $10 \%$ FBS complete medium for only $12 \mathrm{~h}$, a large number of PAS positive cells appeared. Since $2 \%$ HS was present during the induction process for 12 days, the serum condition could only be related to some factors of glycogen synthesis but did not affect the hepatic function of induced HP14.5d cells. The purpose of serum is to supply glucose, vitamins, amino acids and other essential nutrients for cell culture $(34,35)$. Low levels of glycogen synthesis following culture in $2 \%$ HS may be due to: i) Low serum concentrations of serum contain low level of glucose, therefore, the shortage of raw materials limits the product of glycogen; ii) since glycogen synthesis is a series of 
A
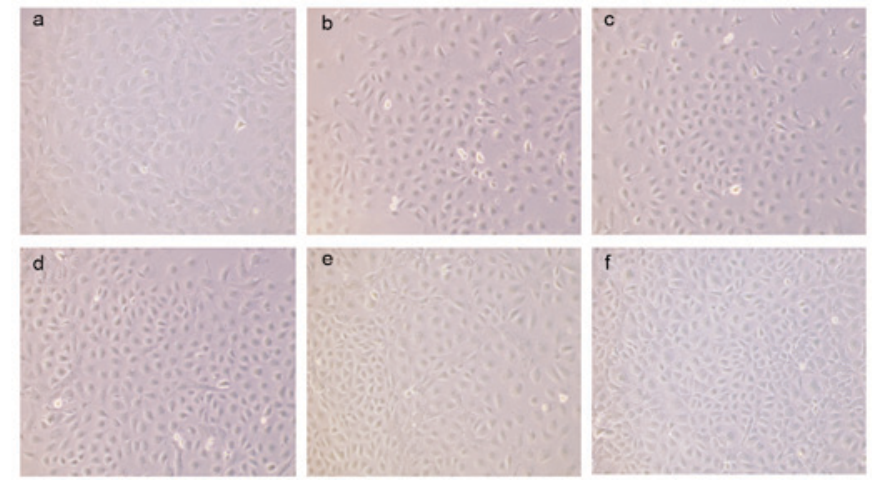

B
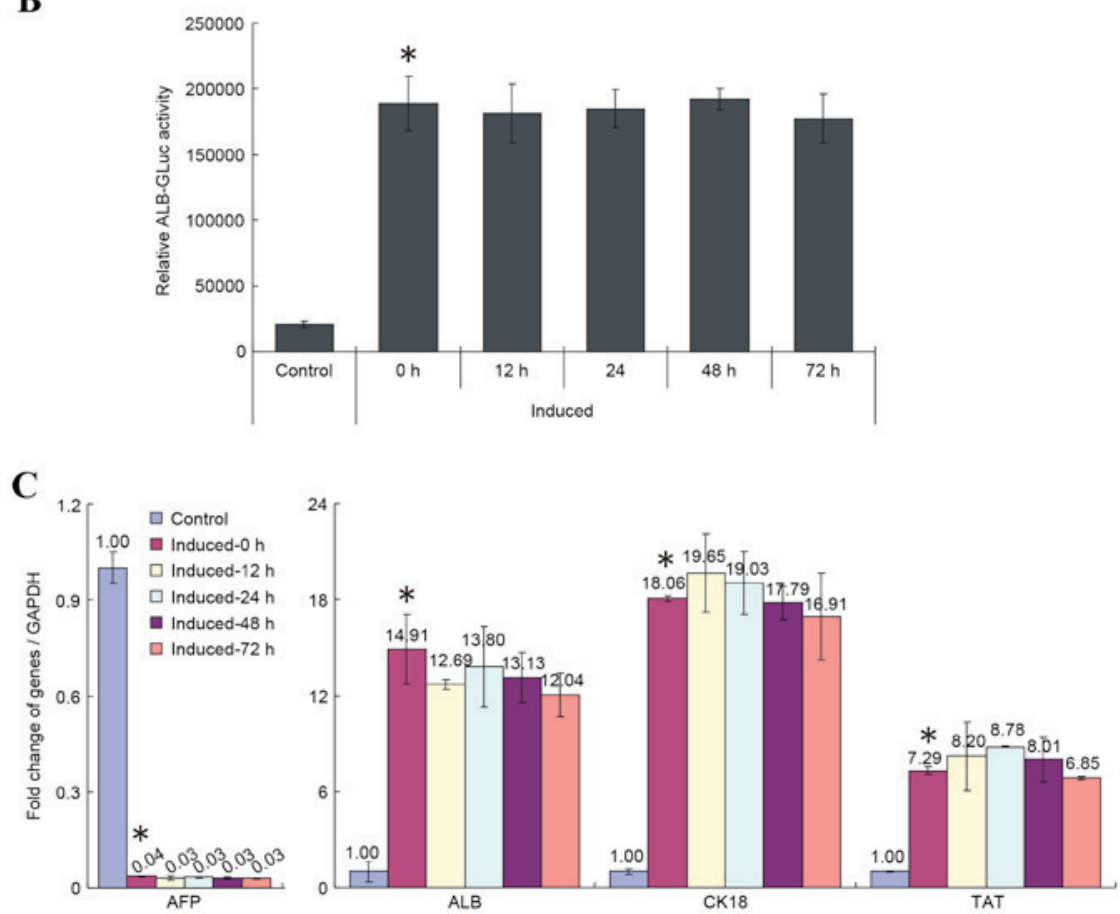

Figure 4. Replacement of 2\% HS with 10\% FBS following 12 days of induction does not influence the induced differentiation of HP14.5d cells. HP14.5d cells were treated with DMEM containing $2 \% \mathrm{HS}+0.1 \mu \mathrm{mol} / 1 \mathrm{Dex}+10 \mathrm{ng} / \mathrm{ml} \mathrm{HGF}+20 \mathrm{ng} / \mathrm{ml} \mathrm{FGF} 4$ for 12 days, then the induction medium was replaced with complete DMEM with 10\% FBS + $0.1 \mu \mathrm{mol} / 1 \mathrm{Dex}+10 \mathrm{ng} / \mathrm{ml} \mathrm{HGF}+20 \mathrm{ng} / \mathrm{ml}$ FGF4 for different time periods: (a) Uninduced HP14.5d cells as control; (b) HP14.5d cells induced for 12 days with no media shift; (c) HP14.5d cells induced for 12 days and induction medium changed for $12 \mathrm{~h}$; (d) HP14.5d cells induced for 12 days and induction medium changed for $24 \mathrm{~h}$; (e) HP14.5d cells induced for 12 days and induction medium changed for 48 h; (f) HP14.5d cells induced for 12 days and induction medium changed for 72 h. (A) HP14.5d cell morphologies. Photomicrographs were captured under x200 magnification. (B) ALB-GLuc activity in HP14.5d cells. "P<0.05 vs. control ( $\mathrm{n}=3$ ). (C) Semi-quantitative reverse transcription-polymerase chain reaction analysis of mRNA expression levels of hepatic related genes AFP, ALB, CK 18 and TAT. "P $<0.05$ vs. control ( $\mathrm{n} \geq 3$ ). HS, horse serum; FBS, fetal bovine serum; DMEM, Dulbecco's modified Eagle's medium; Dex, dexamethasone; HGF, hepatic growth factor; FGF4, fibroblast growth factor 4; ALB, albumin; GLuc, Gaussia luciferase; AFP, $\alpha$ fetoprotein; CK18, keratin 18; TAT, tyrosine aminotransferase.

biochemical reactions catalyzed by specific enzymes $(36,37)$, $2 \%$ HS may not supply enough amino acids to produce glycogen synthase kinase, thereby reducing the amount of intracellular glycogen synthesis, thus affecting the results of PAS staining.

The morphology of cells did not vary according to the time incubated in induction medium containing $10 \%$ FBS, however, the cell density increased with longer culture times in $10 \%$ FBS induction medium. Proliferation and differentiation are generally considered to be mutually exclusive, since differentiation is suppressed during the proliferative phase, and the proliferative abilities of cells in specific differentiation stages are weakened (38-40). In the present study, $2 \%$ HS was observed to favor differentiation of HP14.5d cells, while inhibiting their proliferative abilities. Replacement of $2 \%$ HS with $10 \%$ FBS induction medium did not affect the expression of differentiation related markers and ICG uptake, indicating that HP14.5d cells were matured and differentiated following treatment for 12 days in $2 \%$ HS induction medium. Therefore, the PAS staining method did not accurately reflect the maturity and synthesis function of hepatic cells in $2 \% \mathrm{HS}$ culture conditions.

The present study investigated the role of $2 \%$ HS in the differentiation of HP14.5d cells and verified the negative effect of 2\% HS on glycogen synthesis. Therefore, it may be hypothesized that PAS staining is not a reliable method for evaluating hepatic cell function following stem cell induction in an environment containing $2 \%$ HS. In order to use PAS staining to determine glycogen synthesis, $2 \%$ HS should be replaced with $10 \%$ FBS in the culture medium following induction. The results of the present study suggested that induction media including $2 \%$ HS may have potential as an 
effective method to induce hepatic differentiation, and that PAS staining may be used to evaluate the functionality of $2 \%$ HS-induced hepatocytes.

\section{Acknowledgements}

The present study was supported by the National Natural Science Foundation of China (grant no. 81100309).

\section{References}

1. Kadyk LC, Collins LR, Littman NJ and Millan MT: Proceedings: Moving toward cell-based therapies for liver disease. Stem Cells Transl Med 4: 207-210, 2015.

2. Huebert RC and Rakela J: Cellular therapy for liver disease. Mayo Clin Proc 89: 414-424, 2014.

3. Dalgetty DM, Medine CN, Iredale JP and Hay DC: Progress and future challenges in stem cell-derived liver technologies. Am J Physiol Gastrointest Liver Physiol 297: G241-G248, 2009.

4. Haridass D, Narain N and Ott M: Hepatocyte transplantation: Waiting for stem cells. Curr Opin Organ Transplant 13: 627-632, 2008.

5. Ichinohe N, Kon J, Sasaki K, Nakamura Y, Ooe H, Tanimizu N and Mitaka T: Growth ability and repopulation efficiency of transplanted hepatic stem cells, progenitor cells, and maturehepatocytes in retrorsine-treated rat livers. Cell Transplant 21: 11-22, 2012.

6. Schwartz RE, Fleming HE, Khetani SR and Bhatia SN Pluripotent stem cell-derived hepatocyte-like cells. Biotechnol Adv 32: 504-513, 2014.

7. Pournasr B, Asghari-Vostikolaee $\mathrm{MH}$ and Baharvand $\mathrm{H}$ : Transcription factor-mediated reprograming of fibroblasts to hepatocyte-like cells. Eur J Cell Biol 94: 603-610, 2015.

8. Mu N, Liu HB, Meng QH, Du DW, Jiang Y and Hu HZ: The differentiation of human multipotent adult progenitor cells into hepatocyte-like cells inducedby coculture with human hepatocyte line L02. Ann Surg Treat Res 88: 1-7, 2015.

9. Herrero A,Prigent J,Lombard C, Rosseels V, Daujat-Chavanieu M, Breckpot K, Najimi M,Deblandre G and Sokal EM: Adult-derived human liver stem/progenitor cells infused 3 days postsurgery improve liver regeneration in a mouse model of extended hepatectomy. Cell Transplant 26: 351-354, 2017.

10. He Y, Zhang WY, Gong M, Huang JY, Tang N, Feng T, Wei GH, $\mathrm{He} \mathrm{TC}$ and $\mathrm{Bi}$ Y: Low serum concentration facilitates the differentiation of hepatic progenitor cells. Saudi Med J 32: 128-134, 2011.

11. Bi Y, He Y, Huang JY, Xu L, Tang N, He TC and Feng T: Induced maturation of hepatic progenitor cells in vitro. Braz J Med Biol Res 46: 559-566, 2013.

12. Cho YA, Noh K, Jue SS, Lee SY and Kim EC: Melatonin promotes hepatic differentiation of human dental pulp stem cells: Clinical implications for the prevention of liver fibrosis. J Pineal Res 58: 127-135, 2015.

13. Pal R, Mamidi MK, Das AK and Bhonde R: Diverse effects of dimethyl sulfoxide (DMSO) on the differentiation potential of human embryonic stem cells. Arch Toxicol 86: 651-661, 2012.

14. Bi Y, He Y, Huang J, Su Y, Zhu GH, Wang Y, Qiao M, Zhang BQ, Zhang H, Wang Z. et al: Functional characteristics of reversibly immortalized hepatic progenitor cells derived from mouse embryonic liver. Cell Physiol Biochem 34: 1318-1338, 2014.

15. Bi Y, Huang J, He Y, Zhu GH, Su Y, He BC, Luo J, Wang Y, Kang Q, Luo Q, et al: Wnt antagonist SFRP3 inhibits the differentiation of mouse hepatic progenitor cells. J Cell Biochem 108: 295-303, 2009.

16. Koressaar T and Remm M: Enhancements and modifications of primer design program Primer3. Bioinformatics 23: 1289-1291, 2007.

17. Untergasser A, Cutcutache I, Koressaar T, Ye J, Faircloth BC Remm M and Rozen SG: Primer3-new capabilities and interfaces. Nucleic Acids Res 40: e115, 2012.

18. Livak KJ and Schmittgen TD: Analysis of relative gene expression data using real-time quantitative PCR and the 2(-Delta Delta C(T)) Method. Methods 25: 402-408, 2001.

19. Wille T, Blank K, Schmidt C, Vogt V and Gerlach RG: Gaussia princeps luciferase as a reporter for transcriptional activity, protein secretion, and protein-protein interactions in Salmonella enterica serovar typhimurium. Appl Environ Microbiol 78: 250-257, 2012
20. He Y, Cui J, He T and Bi Y: 5-azacytidine promotes terminal differentiation of hepatic progenitor cells. Mol Med Rep 12: 2872-2878, 2015.

21. He Y, Zhou JW, Xu L, Gong MJ, He TC and Bi Y: Comparison of proliferation and differentiation potential between mouse primary hepatocytes and embryonic hepatic progenitor cells in vitro. Int J Mol Med 32: 476-484, 2013.

22. Yarygin KN, Lupatov AY and Kholodenko IV: Cell-based therapies of liver diseases: Age-related challenges. Clin Interv Aging 10: 1909-1924, 2015.

23. Christ B, Brückner S and Winkler S: The therapeutic promise of mesenchymal stem cells for liver restoration. Trends Mol Med 21: 673-686, 2015.

24. Hindley CJ, Mastrogiovanni G and Huch M: The plastic liver: Differentiated cells, stem cells, every cell? J Clin Invest 124: 5099-5102, 2014.

25. Tolosa L, Caron J, Hannoun Z, Antoni M, López S, Burks D, Castell JV, Weber A, Gomez-Lechon MJ and Dubart-Kupperschmitt A: Transplantation of hESC-derived hepatocytes protects mice from liver injury. Stem Cell Res Ther 6: 246, 2015.

26. $\mathrm{Hu} \mathrm{C}$ and $\mathrm{Li} \mathrm{L}$ : In vitro and in vivo hepatic differentiation of adult somatic stem cells and extraembryonic stem cells for treating end stage liver diseases. Stem Cells Int 2015: 871972, 2015.

27. Kamiya A: Regulation of the survival and differentiation of hepatic stem/progenitor cells by acyclic retinoid. Stem Cell Res Ther 6: 109, 2015.

28. Liu WH, Ren LN, Chen T, You N, Liu LY, Wang T, Yan HT, Luo $\mathrm{H}$ and Tang LJ: Unbalanced distribution of materials: The art of giving rise to hepatocytes from liver stem/progenitor cells. J Cell Mol Med 18: 1-14, 2014.

29. Tsuchiya A, Heike T, Fujino H, Shiota M, Umeda K, Yoshimoto M, Matsuda Y, Ichida T, Aoyagi Y and Nakahata T: Long-term extensive expansion of mouse hepatic stem/progenitor cells in a novel serum-free culture system. Gastroenterology 128: 2089-2104, 2005.

30. Chen Q, Khoury M, Limmon G, Choolani M, Chan JK and Chen J: Human fetal hepatic progenitor cells are distinct from, but closely related to, hematopoietic stem/progenitor cells. Stem Cells 31: 1160-1169, 2013.

31. Sun GY, Dong LY and An W: Involvement of hepatic stimulator substance in the regulation of hepatoblast maturation into hepatocytes in vitro. Stem Cells Dev 23: 1675-1687, 2014.

32. Waclawczyk S, Buchheiser A, Flögel U, Radke TF and Kögler G: In vitro differentiation of unrestricted somatic stem cells into functional hepatic-like cells displaying a hepatocyte-like glucose metabolism. J Cell Physiol 225: 545-554, 2010.

33. Kang XQ, Zang WJ, Bao LJ, Li DL, Song TS, Xu XL and Yu XJ: Fibroblast growth factor-4 and hepatocyte growth factor induce differentiation of human umbilical cord blood-derived mesenchymal stem cells into hepatocytes. World J Gastroenterol 11: 7461-7465, 2005

34. Zhang W, Liu J, Tabata Y, Meng J and Xu H: The effect of serum in culture on RNAi efficacy through modulation of polyplexes size. Biomaterials 35: 567-577, 2014.

35. Dahl C, Saito H, Nielsen HV and Schiøtz PO: The establishment of a combined serum-free and serum-supplemented culture method of obtaining functional cord blood-derived human mast cells. J Immunol Methods 262: 137-143, 2002.

36. Delgado TC, Silva C, Fernandes I, Caldeira M, Bastos M, Baptista C, Carvalheiro M, Geraldes CF and Jones JG: Sources of hepatic glycogen synthesis during an oral glucose tolerance test: Effect of transaldolase exchange onflux estimates. Magn Reson Med 62: 1120-1128, 2009.

37. Soares AF, Carvalho RA, Veiga FJ and Jones JG: Effects of galactose on direct and indirect pathway estimates of hepatic glycogen synthesis. Metab Eng 12: 552-560, 2010.

38. Yu T, Luo G, Zhang L, Wu J, Zhang H and Yang G: Leptin promotes proliferation and inhibits differentiation in porcine skeletal myoblasts. Biosci Biotechnol Biochem 72: 13-21, 2008.

39. Zhang J, Wang B, Xiao Z, Zhao Y, Chen B, Han J, Gao Y, Ding W, Zhang $\mathrm{H}$ and Dai J: Olfactory ensheathing cells promote proliferation and inhibit neuronal differentiation of neural progenitor cells through activation of Notch signaling. Neuroscience 153: 406-413, 2008

40. Chen P, Rossi N, Priddy S, Pierson CR, Studebaker AW and Johnson RA: EphB2 activation is required for ependymoma development as well as inhibits differentiation and promotes proliferation of the transformed cell. Sci Rep 5: 9248, 2015. 